(2) Open Access Full Text Article

\title{
Improving basic life support training for medical students
}

This article was published in the following Dove Press journal:

Advances in Medical Education and Practice

9 April 2016

Number of times this article has been viewed

\section{Mariam Lami \\ Pooja Nair \\ Karishma Gadhvi \\ Faculty of Medicine, Imperial College London, London, UK}

\begin{abstract}
Questions have been raised about basic life support (BLS) training in medical education. This article addresses the research evidence behind why BLS training is inadequate and suggests recommendations for improving BLS training for medical students.
\end{abstract}

Keywords: medical education, basic life support

\section{Introduction}

Cardiac arrests and other life-threatening emergencies are crucial public health issues, where fast recognition and a skilled response can prevent potentially devastating outcomes. Competence in providing immediate life support and cardiopulmonary resuscitation (CPR) is outlined as a prerequisite for doctors by the General Medical Council. ${ }^{1}$ However, there is a growing concern about the lack of emphasis placed on teaching and reinforcing basic life support (BLS) skills within the medical school curriculum. With current training, would medical students confidently be able to initiate effective life-saving CPR?

\section{Discussion}

The general consensus is no. A UK-based survey established that $>60 \%$ of fourth-year medical students lacked confidence in dealing with cardiac arrest situations. ${ }^{2}$ This is despite a shared understanding that resuscitation skills are fundamental. Interestingly, Pillow et $\mathrm{al}^{3}$ revealed that $>35 \%$ of final-year medical students were reluctant to participate in resuscitations as they felt unprepared. Likewise, as medical students, the thought of being the first responder in an emergency setting evokes a similar fear in us. Is inadequate training, and thus lack of competency, the basis for this fear?

Several studies have shown that medical students fall short of the required standards for successful resuscitation. Of note, a survey assessing competence in BLS revealed that more than half of the first-year clinical students did not know to assess the airway after checking for danger and calling for help. ${ }^{4}$ Moreover, under simulated conditions, the average compression rate of student participants was considerably below the BLS recommendations. ${ }^{5}$ It is well known that meeting the compression rate improves survival following resuscitation. ${ }^{6}$ We propose that the lack of competency may be due to ineffective training, poor retention of skills, and minimal assessment.

In order to refine the current BLS curriculum for medical students, the method and frequency of training need to be revised. Currently, most of the medical schools
Correspondence: Mariam Lami

Department of Medicine, South Kensington Campus, Imperial College,

Sir Alexander Fleming Building,

Exhibition Road, London SW7 2AZ, UK

Tel +442075895III

Email mariam.lamil I@imperial.ac.uk
Dovepress

http://dx.doi.org/|0.2147/AMEP.S1021 |

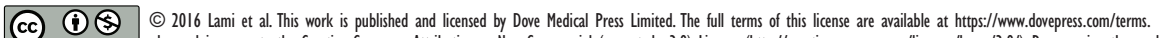
you hereby

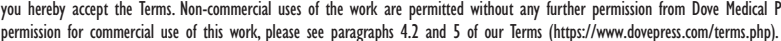


in UK employ instructor training with plastic mannequins as the primary method for CPR training. Other ways to train medical students could be the use of novel techniques such as high-fidelity simulation environments or voice-assisted mannequins. Wik et $\mathrm{al}^{7}$ found that mannequins providing feedback through automated messages according to CPR parameters led to vast improvement in CPR skills when compared with no feedback. Although both these novel techniques improve the acquisition of CPR skills, a formal cost-benefit analysis is necessary to determine their utility in medical education. The technique of training may not need to be changed; instead, regular reinforcement after initial training could be through simple testing rather than full retraining. Mpotos et $\mathrm{al}^{8}$ recently emphasized the efficacy of repetitive formative self-testing in improving the retention of CPR skills. Further repetition of these essential skills may also be encouraged through "learning by teaching". Breckwoldt et $\mathrm{al}^{9}$ demonstrated that medical students who taught BLS skills to schoolchildren had better practical skills compared to students who only underwent conventional training. Additionally, teaching these vital skills to schoolchildren can further contribute toward improved public awareness of BLS. However, further research is needed to identify the most efficient and cost-effective way to train medical students.

The intervals between refresher courses for medical students to effectively maintain their CPR skills have been reviewed. Following a 6-month refresher course after initial training, medical students retained their skills for up to a year. ${ }^{10}$ However, depending on the type of refresher course, this may not be feasible for medical schools in terms of cost and other logistical issues.

In summary, we propose early introduction of BLS training in the medical curriculum followed by regular reinforcement using compulsory online tests. This will be a cost-effective method and is most likely to lead to high adoption by medical schools. An optimal online test needs to be investigated.
Newly qualified doctors will undoubtedly be placed in emergency situations where they are expected to apply BLS skills. Therefore, the issue of low confidence in resuscitation skills among medical students needs to be addressed.

"Preparation through education is less costly than learning through tragedy" [Max Mayfield]. ${ }^{11}$

\section{Disclosure}

The authors report no conflicts of interest in this work.

\section{References}

1. General Medical Council. Tomorrow's Doctors. UK: General Medical Council;2010.

2. Graham CA, Guest KA, Scollon D. Cardiopulmonary resuscitation. Paper 2: a survey of basic life support training for medical students. J Accid Emerg Med. 1994;11(3):165-167.

3. Pillow MT, Stader D, Nguyen M, Cao D, McArthur R, Hoxhaj S. Perceptions of basic, advanced, and pediatric life support training in a United States medical school. J Emerg Med. 2014;46(5):695-700.

4. Behrend T, Heineman J, Wu L, et al. Retention of cardiopulmonary resuscitation skills in medical students utilizing a high-fidelity patient simulator. Med Student Res J. 2011;1(1):1-4.

5. Phillips PS, Nolan JP. Training in basic and advanced life support in UK medical schools: questionnaire survey. BMJ. 2001;323(7303):22-23.

6. Hüpfl M, Selig HF, Nagele P. Chest-compression-only versus standard cardiopulmonary resuscitation: a meta-analysis. Lancet. 2010;376(9752):1552-1557.

7. Wik L, Myklebust H, Auestad BH, Steen PA. Retention of basic life support skills 6 months after training with an automated voice advisory manikin system without instructor involvement. Resuscitation. 2002;52(3):273-279.

8. Mpotos N, De Wever B, Cleymans N, et al. Repetitive sessions of formative self-testing to refresh CPR skills: a randomised non-inferiority trial. Resuscitation. 2014;85(9):1282-1286.

9. Breckwoldt J, Beetz D, Schnitzer L, Waskow C, Arntz H, Weimann J. Medical students teaching basic life support to school children as a required element of medical education: a randomised controlled study comparing three different approaches to fifth year medical training in emergency medicine. Resuscitation. 2007;74(1):158-165.

10. Nishiyama C, Iwami T, Murakami Y, et al. Effectiveness of simplified 15-min refresher BLS training program: a randomized controlled trial. Resuscitation. 2015;90:56-60.

11. Challener CA. Hurricane season rapidly approaches: lessons learned and tips for weathering the next storm. Available from: http://www. chemalliance.org/featured $/$ sec $=5 \& \mathrm{id}=7017$. Accessed 21st March 2016.
Advances in Medical Education and Practice

\section{Publish your work in this journal}

Advances in Medical Education and Practice is an international, peerreviewed, open access journal that aims to present and publish research on Medical Education covering medical, dental, nursing and allied health care professional education. The journal covers undergraduate education, postgraduate training and continuing medical education

\section{Dovepress}

including emerging trends and innovative models linking education, research, and health care services. The manuscript management system is completely online and includes a very quick and fair peer-review system. Visit http://www.dovepress.com/testimonials.php to read real quotes from published authors. 